\title{
Kernos
}

Revue internationale et pluridisciplinaire de religion grecque antique

$34 \mid 2021$

Varia

\section{Rituels en image - Images de rituel. Iconographie - histoire des religions - archéologie}

\section{Vasso Zachari}

\section{(2) OpenEdition}

\section{Journals}

Édition électronique

URL : https://journals.openedition.org/kernos/3983

DOI : 10.4000/kernos.3983

ISSN : 2034-7871

\section{Éditeur}

Centre international d'étude de la religion grecque antique

\section{Édition imprimée}

Date de publication : 31 décembre 2021

Pagination : 304-306

ISBN : 978-2-87562-305-8

ISSN : 0776-3824

\section{Référence électronique}

Vasso Zachari, «Rituels en image - Images de rituel. Iconographie - histoire des religions archéologie », Kernos [En ligne], 34 | 2021, mis en ligne le 31 décembre 2021, consulté le 15 mars 2023. URL : http://journals.openedition.org/kernos/3983 ; DOI : https://doi.org/10.4000/kernos.3983

Ce document a été généré automatiquement le 15 mars 2023.

Tous droits réservés 


\title{
Rituels en image - Images de rituel. Iconographie - histoire des religions - archéologie
}

\author{
Vasso Zachari
}

\section{RÉFÉRENCE}

Anne-Françoise JACCOTTET (dir.), Rituels en image - Images de rituel. Iconographie - histoire des religions - archéologie, Berne, Peter Lang, 2021. 1 vol. 21,5 × $30 \mathrm{~cm}, 262$ p. $+47 \mathrm{pl}$. ISBN : 978-3-0343-3908-7.

1 Rituels et images sont mis en miroir dès le titre, annonçant d'emblée le sujet traité dans cet ouvrage collectif soigneusement édité par Anne-Françoise Jaccottet. Au croisement de l'iconographie, de l'histoire des religions et de l'archéologie, dix-neuf contributions mettent en lumière des points précis questionnant les liens réciproques entre images et rituels et donnent à cette publication un caractère remarquable. Ce recueil d'études s'inscrit dans le prolongement d'autres ouvrages connus du monde francophone ${ }^{1}$. Par sa pluralité et son ouverture à d'autres civilisations il constitue un apport considérable à la recherche dans ce domaine.

Dans l'introduction, l'éditrice ouvre la discussion en traçant les axes principaux, les fils conducteurs et les questions abordées dans l'ouvrage à travers l'analyse d'un dossier iconographique sur l'autel de Vespasien à Pompéi et les reliefs mysiens. La première partie rassemble quatre contributions qui ont pour objet l'analyse de la construction de l'image rituelle. Que ce soit en étudiant différents supports d'images rituelles (Fr. Lissarrague), ou en se centrant sur l'iconographie sacrificielle de la céramique attique (M. Halm-Tisserant), les artisans opèrent des choix pertinents dans la création des montages et des syntaxes visuelles, en mettant en avant les éléments saillants et les étapes fondamentales du rite. De même, concernant des images étrusques (L. Hugot) et mésopotamiennes (A.-C. Rendu Loisel), la juxtaposition avec d'autres comparanda 
visuels et des sources textuelles, quand cela est possible, permet d'identifier les personnages dans leurs rôles rituels et sociaux, et de déchiffrer les ambiguïtés afin de mieux comprendre la façon dont l'espace rituel est traité au figuré, ainsi que selon la réalité archéologique. Comme le démontrent les articles ici réunis, l'image rituelle est circonscrite par les notions de spatialité et de gestualité des participants avec des objets manipulés ou simplement représentés dans la scène, contribuant ainsi à une communication efficace avec la sphère divine.

3 La deuxième partie intitulée « ambiances rituelles » explore un des volets de la relation de l'image rituelle avec son contexte, d'après la céramique attique et la peinture romaine. L'étude de l'imagerie dionysiaque et de l'entourage du dieu au milieu du $v^{\mathrm{e}} \mathrm{s}$. av. J.-C. (C. Isler-Kerényi) et sur les vases plus tardifs (A. Verbanck-Piérard) à travers la connectivité entre les deux faces du vase et la mise en scène autour de la divinité honorée permet d'établir et de comprendre les innovations et transformations iconographiques, ainsi que les nouveaux schémas figuratifs émergeants. Quant aux dispositifs rituels dans les paysages « sacro-idylliques » (S. Wyler), les peintres romains combinent de façon fantasmée des éléments du réalisme et des conventions symboliques pour construire un imaginaire de la pietas dans un espace rituel limitrophe de la cité. En se penchant attentivement sur les détails évocateurs de chaque image, on comprend mieux la façon dont ils reflètent l'imagination et la sensibilité des peintres face aux changements observés au niveau rituel, historique et culturel et par conséquent aux atmosphères évoquées, aboutissant au rapprochement entre les divinités et les humains.

4 La troisième partie consacrée à l'iconographie des objets rituels vise à dévoiler leur double valeur, fonctionnelle et symbolique. Certains objets sont organiquement liés à des pratiques rituelles comme l'attestent les vases hittites (P. Michel), les cruches à haut col érétriens (S. Huber), ainsi que les autels romains (V. Huet). Leur rapport étroit avec les images qu'ils portent décrit le contexte dans lequel ils étaient utilisés, crée une mise en abyme du rituel et sert de memento en guise d'image exemplaire à imiter et à reproduire. Dans tous les cas, un rapport d'activation réciproque s'établit entre chaque image et le rituel concerné. Par ailleurs, l'analyse de la représentation de l'anneau d'attache du faisceau de l'initié éleusinien sur des supports figurés variés (Chr. Mitsopoulou) permet de retracer son utilisation lors des mystères et de cerner tant le lien établi entre les paraphernalia rituels, ainsi que le décalage flagrant entre son importance dans les images et son absence dans les realia archéologiques, tout en proposant une interprétation économique. Ainsi, ces contributions démontrent comment, par la répétition, certains détails iconographiques - objets, gestes et séquences - deviennent des éléments autonomes, des abréviations parlantes pour des rituels exécutés.

Dans la quatrième partie, les articles explorent les images rituelles en contexte, c'est-àdire selon leur lieu de provenance ou d'exposition, notamment l'espace du sanctuaire et du temple. Plus précisément, les tableaux votifs en terre cuite de Locres (H. Collard), le trône bachique de Bolsena (J.-M. Pailler) et les représentations sacrificielles sur les monnaies et les reliefs votifs romains provenant de l'Asie Mineure (G. Schörner) ouvrent de nouvelles voies pour comprendre les pratiques rituelles à l'échelle régionale. En prenant en considération les modalités d'utilisation et de réception des images, ces textes apportent une contribution précieuse au cadre interprétatif qui demeure encore trop centré autour d'Athènes et de Rome, même pour les images 
produites en dehors de ces villes. Le relief d'Argénidas, d'origine laconienne, fait partie de ces exceptions notables, car sa découverte en Vénétie était surprenante (S. Estienne). En reconstituant sa biographie possible et en contextualisant son iconographie originale, le spectateur comprend mieux sa singularité comme objet de piété personnalisée. Last but not least, Claude Bérard nous embarque dans l'univers chrétien orthodoxe, son nouveau tournant iconique, pour parler du dynamisme du rituel en images dont la valeur liturgique et symbolique prend sens lors de la Grande Entrée et sous les sons de l'hymne de chérubins. Enfin, en guise de conclusion, deux contributions - l'une sur les images divines, leur création et leur place dans la cité (A. Schnapp) et l'autre sur les rapports entre textes et images selon les images mithriaques ( $\mathrm{N}$. Belayche) -, se lisent dans la complémentarité et prolongent la réflexion sur les rituels en images et les images de rituels.

Lors de ce parcours, le rituel du sacrifice est analysé à de nombreuses reprises et devient ainsi un cas éloquent pour comprendre les complexités du dossier abordé dans cette publication. Le sacrifice dans les systèmes polythéistes consiste en général en la mise à mort d'un animal à une puissance divine de la part d'un individu qui lui demande un vœu ou la remercie d'en avoir exaucé un. Le rendu iconique de ce rituel est une démarche délicate pour les artisans qui sont confrontés à saisir l'insaisissable et à rendre statique une action qui mobilisait de nombreuses personnes, animaux, objets, paroles, mouvements et sensations. Les choix opérés sont déterminés notamment par leur culture et le support de l'image. Le schéma iconographique le plus répandu vise à mettre en avant le dédicant, le don et le destinataire, ainsi que le lieu de l'action, le plus souvent un autel. Ce schéma se décline en plusieurs variations avec l'omission de certains éléments et l'ajout d'autres. Les artisans arrivent même à l'abstraction: ils isolent un détail iconographique et le rendent parlant, comme une métonymie. L'autel, par exemple, objet rituel par excellence, construit l'image où il est représenté : comme signe iconique, il sert souvent à séparer graphiquement les humains des dieux; comme signe symbolique, il devient le lieu où les deux univers communiquent via le rituel. Sa seule présence, même en occupant une place secondaire dans l'image, comme autour des anses du vase, parvient à évoquer l'ambiance rituelle qui n'est pas autrement explicite dans la scène. Enfin, comme support d'image, un autel sacrificiel crée des jeux d'auto-référentialité éloquents avec le rituel effectué et représenté.

7 Dans les études d'iconographie, les images de rituels sont conventionnellement répertoriées parmi les scènes de la vie quotidienne, par opposition aux scènes mythologiques. Or, cette classification s'avère simpliste pour la représentation des humains en activité rituelle avec des objets manipulés et des gestes parfois subtils dont l'identification et le sens restent insaisissables pour les spectateurs modernes. En plus, elle écarte souvent des cas plus énigmatiques dans lesquels les divinités sont partie prenante d'une activité rituelle, partagent le même espace figuratif avec les humains et parfois interagissent avec eux. C'est pourquoi, le présent ouvrage est novateur et de grande importance pour les recherches sur les rituels, abordées à travers le filtre des images comme testimonia, car les articles ici réunis explorent des questions complexes. De plus, les démarches méthodologiques proposées avec les outils théoriques et l'approche sémiologique adoptés aboutissent à des interprétations originales. Enfin, il démontre l'amplitude d'un sujet que l'on croit parfois bien connaître, mais qui, heureusement, nous réserve encore des surprises. 


\section{NOTES}

1. Notamment Image et rituel en Grèce ancienne, Recherches et Documents du Centre Thomas More 48 (1985) et S. ESTIENNE et al. (dir.), Image et Religion dans l'antiquité gréco-romaine, Naples, 2008.

\section{AUTEURS}

VASSO ZACHARI

EHESS - UMR 8210 AnHiMA 